\title{
Experimental comparison of altitudes with modern geodetic methods
}

\author{
Boštjan Kovačiči,* \\ ${ }^{1}$ University of Maribor, Smetanova 17, 2000, Maribor, Slovenia
}

\begin{abstract}
Levelling is one of the most important geodesic works in construction and other interventions in space. Mostly, it is used for the needs of the altitude presentations of the terrain, to determine shifts, to determine the height of the object, and for various precise laboratory and scientific researches. When determining the shifts, the values are confirmed with the results of levelling, and deformations are calculated. There are a lot of methods to determine height differences; which one will be used, depends on the complexity of the works. Recently, the GNSS method is mostly used. It offers $2 \mathrm{D}$ positionally reliable results, whereas the vertical component does not provide reliable results. For this purpose, a series of tests and GNSS-measurements analysis were performed at our institution, which is also presented in the article as the GNSS-measurements analysis in comparison to the results obtained with the robotic total station of accuracy $0,5^{5}$. Prior to the experiment, a temporal GNSS data analysis based on an individual axis and with a different way of data processing was carried out. The planning of GNSS-measurements for the needs of more demanding measurements is emphasised. To improve the determination of the vertical component, the data capture with GNSS method was increased from $10 \mathrm{~Hz}$ to $100 \mathrm{~Hz}$, which partly improved the final values and is presented in the study.
\end{abstract}

\section{Introduction}

The technological development has interfered also in geodesy and thanks to only that, there are instruments with which the difficult tasks, which were unmanageable a while ago, can be done. In this sense, that refers mostly on GNSS instruments and RTS robotic electronic instruments, with which the shifts and deformities of various constructions even on the tenth of the mm accurately is determined. Only with this equipment and results, the answer if the construction during the exploitation acts in accordance with designed solutions is obtained; also, with obtained shifts, important parameters about the condition assessment and construction assurance are obtained. Therefore, construction analysis demands reliable results about an individual axis; based on them, it can be judged if the construction acts in accordance with the model and or given measured values cause the deformities of the construction. When measuring, the focus is on geodetic measurements, which give absolute

\footnotetext{
*Corresponding author: bostjan.kovacic@um.si
} 
results and are, therefore, the only ones in the construction analysis on the terrain which give immediate rough results.

Due to the possibility to determine the $3 \mathrm{D}$ position of the points in an absolute sense with increasing the number of the readings per second, the use of GNSS instruments and robotic total stations is no longer limited only on the monitoring of the static response, but also the on the dynamic analysis of the constructions. Now, the dynamic parameters of build objects, such as natural frequency, damped oscillations and natural forms of oscillation can be determined as well. These dynamic parameters are functions of global stiffness and are the best indicators of the real condition of the construction. Any serious change which happens on the construction could trigger the change of dynamic parameter values [1].

To monitor the measurements of the dynamic response, the experimental analysis of time data capture was executed. In this way, the confirmation on the reliability of data which are gained immediately, compared to results of differently long data capture: $1 \mathrm{~h}, 2 \mathrm{~h}, 6 \mathrm{~h}, 12 \mathrm{~h}$, $24 \mathrm{~h}$, was obtained. After the analysis, the comparative analysis of the GNSS receiver with a robotic total station in the altitude sense was performed; the altitude was changed every minute for $5 \mathrm{~cm}$ and the change with both instruments was monitored. To understand the GNSS function system, it is necessary to view the historical development of this method and instruments.

Until recently, the navigation was based on stars and orientation terrain characteristics. These ways are in use even today since they are quite reliable but were largely dependent on the weather; therefore, the need to create a better orientation and location determination system on Earth was shown. Among more important early achievements in the navigation system was the LORAN system (LOng RAnge Navigation). It consisted of Earth-based transmitters and it enabled for ships and aeroplanes to determine their position (latitude and longitude). The accuracy was only $1.5 \mathrm{~km}$ and thus it was not appropriate for the needs in geodesy [2]. In 1973, the Department of Defense (DOD) started to develop the project NAVSTAR - GPS - NAVigation Satellite Timing And Ranging - Global Positioning System (today is known only as the GPS) which has largely developed until today and is, so to speak, affordable to everyone. In that time, the goal was to determine the position of an individual military unit on the terrain, its speed and time whether resting or moving in each moment, anywhere on Earth and in every weather. First, the network of satellites to control the intercontinental warheads was based; in 1989, the first operational satellite (Block II) flew into the orbit and thus, in 1995, the GPS system was launched in the full scope (Block IIA 18 satellites, Block IIR -6 satellites). Civilians can also use the same system, which the American army did not agree with; they tried to impact on the measurements of the civilians (S/A - Selective Availability or intentional disturbance of the GPS signal). Today, the line between the military and civilian use of the GPS system has been, so to say, blurred; in May 2002, the American government abolished the disturbances for the civilians (S/A) and at the same time, other systems have appeared as well (Kovačič 2004). Nowadays, there are various types of receivers of various accuracies and the emphasis is on the analysis of the results, on the processing, on the planning and on maximising the number of measurements. The GNSS survey measurements are in general divided into absolute and relative [3, 4].

For the accurate determination of the receiver's position in practice, mainly relative survey measurements are used; they enable up to a few cms coordinate accuracy. They need at least two receivers to determine the position; one of them is located on the point with known coordinates and the other on the new point. Relative GNSS survey measurements are static, rapid static, kinematic and RTK measurement method [3].

The rapid static GNSS survey measurement was used in the experiment. Rapid static GNSS survey measurement is in all essential characteristics equal to the static survey measurement; the exception is only a shorter duration period of the observation. The accuracy of this method is from $1 \mathrm{ppm}$ to $10 \mathrm{ppm}$. The observations last from 5 to 20 minutes. 


\section{Measurement and the GNSS results analysis in different time periods}

The referential spot to perform the GNSS surveying measurement was on the roof of the Faculty of Civil Engineering, Transportation Engineering and Architecture (FGPA) in Maribor; thus, the possible disturbances in the satellites' signal were avoided. We used the rapid static measurement which is the basic measurement to determine the relative position, in time intervals $1 \mathrm{~h}, 2 \mathrm{~h}, 6 \mathrm{~h}, 12 \mathrm{~h}$ and $24 \mathrm{~h}$ with three different receivers.

Three different GNSS receivers, which are shown in Figure 1, were used for the needs of the experiment.

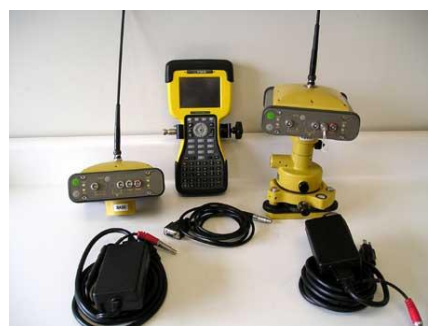

Topcon Hiper Pro

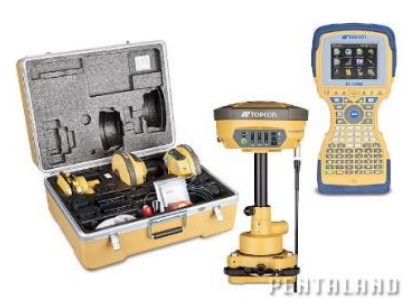

Topcon Hiper V

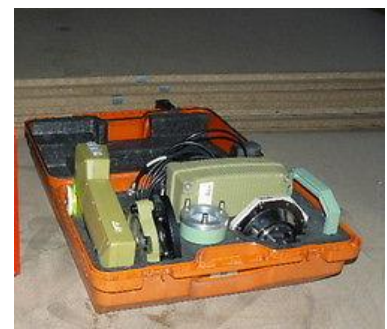

Leica SR9500

Fig. 1. Used GNSS instruments.

The exact ephemerides were included in the final procession of the GNSS surveying measurement. Five continuously working stations of the Signal permanent GNSS network (SLO), two continuously working stations of the APOS permanent GNSS network (AUS) and seven IGS points were included in the processing.

Processed coordinates of the points were determined as the arithmetical mean of the static surveying measurement's coordinates. The calculation of the standard deviation and standard error is presented in equations 1 and 2.

\subsection{Standard deviation}

A very important statistical parameter is the standard deviation $(\sigma)$. It tells us how much the values of the statistical sign deviate from the average. It is also said that standard deviation is the measurement for the dispersion distribution value [5].

$$
\sigma_{x}= \pm \sqrt{\frac{\sum_{i=1}^{N}[v \cdot v]}{(n-1)}}
$$

where:

$\sigma \ldots$ is the standard deviation

$\mathrm{v}$... the deviation from the arithmetical mean

\subsection{The standard error of the arithmetical mean}

The standard error of the arithmetical mean is the standard deviation of the sampling distribution of the arithmetical means and measures the accuracy of the sampling assessment of the arithmetical mean. It tells us in what range are the arithmetical means values which can be claimed with a certain (usually $95 \%$ ) trust interval.

$$
\sigma_{x}^{-}= \pm \sqrt{\frac{\sum_{i=1}^{N}[v \cdot v]}{n \cdot(n-1)}}
$$


Where $\sigma_{x}^{-} \ldots$ is the standard error.

The example of the calculation of the error and accuracy for the HiperPro for $\mathrm{H}$ coordinate is shown in Table 1.

Table 1. The example of the calculation of the error and accuracy for the HiperPro for $\mathrm{H}$ coordinate.

\begin{tabular}{|c|c|c|c|c|c|c|}
\hline & $\mathrm{H}[\mathrm{m}]$ & \multicolumn{2}{|c|}{ deviation from the arithmetical mean } & \multicolumn{2}{|c|}{ the deviation squares } \\
\hline $\mathrm{h}_{1}$ & $1 \mathrm{~h}$ & 285,413 & $\mathrm{v}_{1}=\mathrm{h}^{\prime}-\mathrm{h}_{1}$ & $-0,0212$ & $\mathrm{~V}_{1} * \mathrm{v}_{1}$ & 0,00044944 \\
\hline $\mathrm{h}_{2}$ & $2 \mathrm{~h}$ & 285,202 & $\mathrm{v}_{2}=\mathrm{h}^{\prime}-\mathrm{h}_{2}$ & 0,1898 & $\mathrm{~V}_{2}{ }^{*} \mathrm{v}_{2}$ & 0,03602404 \\
\hline $\mathrm{h}_{3}$ & $6 \mathrm{~h}$ & 285,447 & $\mathrm{v}_{3}=\mathrm{h}^{\prime}-\mathrm{h}_{3}$ & $-0,0552$ & $\mathrm{v}_{3} * \mathrm{v}_{3}$ & 0,00304704 \\
\hline $\mathrm{h}_{4}$ & $12 \mathrm{~h}$ & 285,456 & $\mathrm{~V}_{4}=\mathrm{h}^{\prime}-\mathrm{h}_{4}$ & $-0,0642$ & $\mathrm{~V}_{4} * \mathrm{~V}_{4}$ & 0,00412164 \\
\hline $\mathrm{h}_{5}$ & $24 \mathrm{~h}$ & 285,441 & $\mathrm{v}_{5}=\mathrm{h}^{\prime}-\mathrm{h}_{5}$ & \begin{tabular}{|l|l|}
$-0,0492$ \\
\end{tabular} & $\mathrm{v} 5^{*} \mathrm{v}_{5}$ & 0,00242064 \\
\hline & $\sum$ & 1426,959 & $\sum \mathrm{v}$ & $-5,6843 \mathrm{E}-14$ & $\sum \mathrm{v}^{*} \mathrm{v}$ & 0,0460628 \\
\hline
\end{tabular}

\begin{tabular}{|l|l|l|}
\hline the number of measurements & $\mathrm{n}$ & $\mathbf{5}$ \\
\hline arithmetical mean & $\mathrm{h}^{\prime}$ & $\mathbf{2 8 5 , 3 9 1 8}$ \\
\hline the standard deviation of an individual measurement & $\sigma_{\mathrm{hi}^{i}}$ & $\mathbf{0 , 1 0 7}$ \\
\hline the standard error of the arithmetical mean & $\sigma_{\text {hi }}{ }^{-}$ & $\mathbf{0 , 0 4 8}$ \\
\hline
\end{tabular}

Table 2 and Figure 2 show the standard errors of the arithmetical mean on the type of the antenna.

Table 2. Standard errors of the arithmetical mean on the type of the antenna.

\begin{tabular}{|c|c|c|c|}
\hline & Hyper-pro & Hyper-V & Leica \\
\hline $\mathbf{Y}$ [m] & 0,032 & 0,020 & 0,087 \\
\hline $\mathbf{X}$ [m] & 0,133 & 0,062 & 0,334 \\
\hline $\mathbf{H}[\mathbf{m}]$ & 0,048 & 0,016 & 0,255 \\
\hline
\end{tabular}

\begin{tabular}{|c|c|c|c|}
\hline \multirow{3}{*}{$\begin{array}{r}0.35 \\
0.3 \\
0.25\end{array}$} & \multicolumn{3}{|c|}{0.334} \\
\hline & & -0 & \\
\hline & & & $=0.255$ \\
\hline \multicolumn{4}{|l|}{0.2} \\
\hline \multirow{4}{*}{$\begin{array}{r}0.1 \\
0.05 \\
0\end{array}$} & & & \\
\hline & 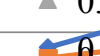 & -0 & $\longrightarrow 0.048$ \\
\hline & & & 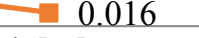 \\
\hline & $\mathrm{Y}[\mathrm{m}]$ & $\mathrm{X}[\mathrm{m}]$ & $\mathrm{h}[\mathrm{m}]$ \\
\hline$\rightarrow$ Leica & 0.087 & 0.334 & 0.255 \\
\hline$\leadsto$ H-pro & 0.032 & 0.133 & 0.048 \\
\hline$-\mathrm{H}-\mathrm{V}$ & 0.02 & 0.062 & 0.016 \\
\hline
\end{tabular}

Fig. 2. Standard errors of the arithmetical means on the type of the antenna.

The DOP factor is used for accuracy in the GNSS data analysis; it especially determines the positional, horizontal and vertical component as shown on Fig.3. 


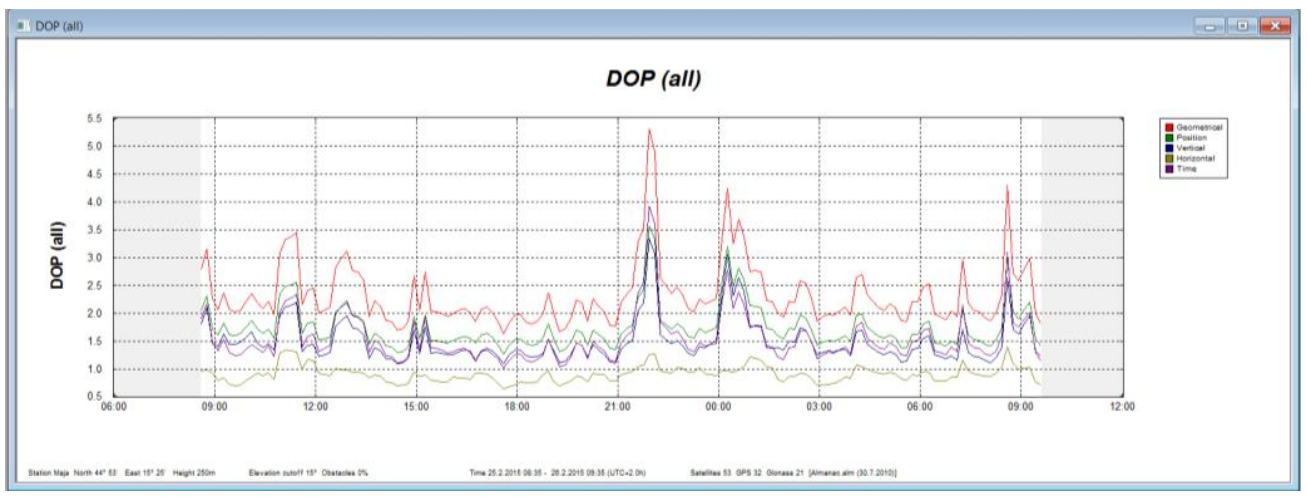

Fig. 3. The value of the DOP factors - without obstacle.

The DOP factors impact on the accuracy since they are linked to the geometrical satellites' arrangement, which must be as small as possible. The PDOP factor was in our case at the Hiper Pro receiver between 2.55 and 2.99, at the Hiper V receiver between 2.37 and 3.66 and at the Leica receiver between 4.46 and 9.29. The highest value of the PDOP factor is at the Leica receiver which is shown at the accuracy of the coordinates.

Tables 3, 4 and 5 and Fig 4 show the average value of the number of the satellites and DOP factors according to the receiver.

Table 3. Average values of the number of satellites and DOP factors.

\begin{tabular}{|c|c|c|c|c|c|c|}
\hline Hiper Pro & GPS & GLONASS & SUM & PDOP & HDOP & VDOP \\
\hline $\mathbf{1} \mathbf{~ h}$ & 11 & 5 & 16 & 2,639 & 1,388 & 2,243 \\
\hline $\mathbf{2} \mathbf{~ h}$ & 12 & 7 & 19 & 2,764 & 1,564 & 2,266 \\
\hline $\mathbf{6} \mathbf{~ h}$ & 18 & 12 & 30 & 2,757 & 1,551 & 2,273 \\
\hline $\mathbf{1 2} \mathbf{~ h}$ & 27 & 16 & 43 & 2,996 & 1,577 & 2,547 \\
\hline $\mathbf{2 4} \mathbf{~ h}$ & 31 & 19 & 50 & 2,551 & 1,340 & 2,171 \\
\hline
\end{tabular}

Table 4. Average value of the number of satellites and DOP factors.

\begin{tabular}{|c|c|c|c|c|c|c|}
\hline Hiper V & GPS & GLONASS & SUM & PDOP & HDOP & VDOP \\
\hline $\mathbf{1 ~ h}$ & 10 & 8 & 18 & 2,379 & 1,279 & 2,006 \\
\hline $\mathbf{2} \mathbf{~ h}$ & 12 & 8 & 20 & 2,608 & 1,327 & 2,245 \\
\hline $\mathbf{6} \mathbf{~ h}$ & 16 & 13 & 29 & 2,992 & 1,424 & 2,632 \\
\hline $\mathbf{1 2} \mathbf{~ h}$ & 24 & 17 & 41 & 3,237 & 1,693 & 2,757 \\
\hline $\mathbf{2 4} \mathbf{~ h}$ & 30 & 18 & 48 & 3,662 & 1,976 & 3,075 \\
\hline
\end{tabular}

Table 5. Average value of the number of satellites and DOP factors.

\begin{tabular}{|c|c|c|c|c|c|c|}
\hline Leica & GPS & GLONASS & SUM & PDOP & HDOP & VDOP \\
\hline $\mathbf{1} \mathbf{h}$ & 7 & 0 & 7 & 9,296 & 6,616 & 6,522 \\
\hline $\mathbf{2} \mathbf{h}$ & 8 & 0 & 8 & 4,460 & 2,609 & 3,616 \\
\hline $\mathbf{6} \mathbf{h}$ & 11 & 0 & 11 & 6,223 & 3,859 & 4,881 \\
\hline $\mathbf{1 2} \mathbf{h}$ & 22 & 0 & 22 & 8,300 & 4,924 & 6,665 \\
\hline $\mathbf{2 4} \mathbf{~ h}$ & 30 & 0 & 30 & 9,063 & 4,837 & 7,651 \\
\hline
\end{tabular}

Figure 4 shows the average values of the PDOP factors according to the type of the antenna. 


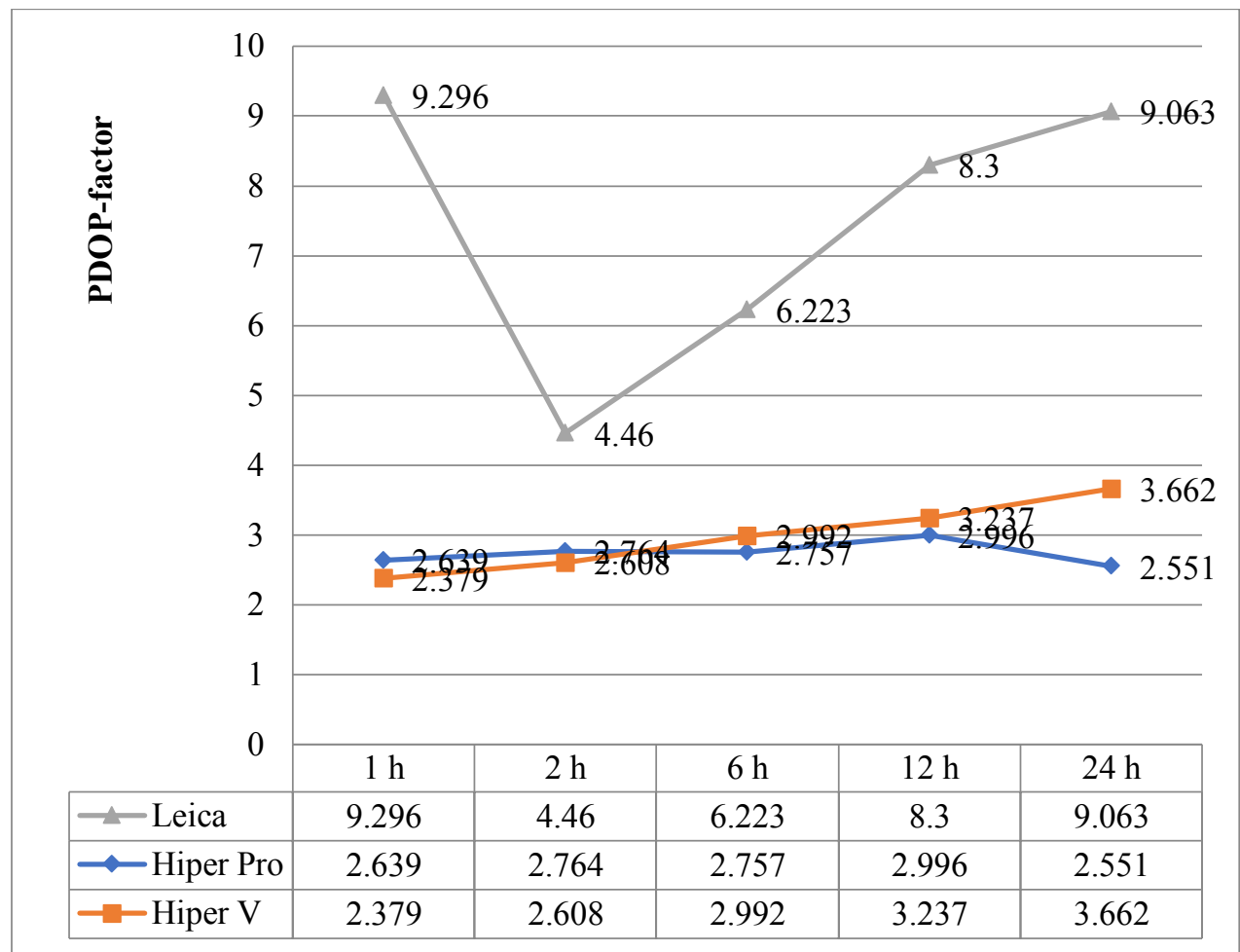

Fig. 4. Average values of the PDOP factors according to the type of the antenna.

If the accuracy of the position determination between all three receivers is compared, a major difference between the Topcon Hiper V and Leica SR9500 is noted. It is seen from Table 6, that the results which are obtained with the Topcon Hiper V antenna are the most accurate. Topcon Hiper V is 226 channel GNSS receiver and is one of the newest GNSS antennas on the market. Leica SR9500 is in our case the least accurate receiver. It is the oldest model and receives only the GPS system's satellites. The Leica receiver cannot monitor the GLONASS satellites. It can only monitor from 7 to 30 satellites. The differences are obvious at longer vectors, in our case the X coordinate. All three axis have been processed in the experiment, but since the emphasis is on a determination of the altitude component for the dynamic and static construction analysis, the focus will be only on the $\mathrm{H}$ coordinate.

Table 6. Coordinate $\mathrm{H}$ according to the duration period.

$-1 \mathrm{~h}$

\begin{tabular}{|c|c|c|c|c|c|c|}
\hline & \multirow{3}{*}{$\frac{\mathrm{h}[\mathrm{m}]}{285,4130}$} & \multirow{2}{*}{\multicolumn{2}{|c|}{ deviation from the arithmetical mean }} & \multirow{2}{*}{\multicolumn{2}{|c|}{ the deviation squares }} \\
\hline & & & & & & \\
\hline Topcon Hiper Pro & $1 \mathrm{~h}$ & & $\mathrm{~V}_{1}=\mathrm{H}^{\prime}-\mathrm{H}_{1}$ & 0,450333333 & $\mathrm{~V} 1_{1}^{*} \mathrm{v}_{1}$ & 0,202800111 \\
\hline Topcon Hiper V & $1 \mathrm{~h}$ & 285,4240 & $\mathrm{~V}_{2}=\mathrm{H}^{\prime}-\mathrm{H}_{2}$ & 0,439333333 & $\mathrm{~V}_{2} * \mathrm{~V}_{2}$ & 0,193013778 \\
\hline Leica & $1 \mathrm{~h}$ & 286,753 & $\mathrm{~V}_{3}=\mathrm{H}^{\prime}-\mathrm{H}_{3}$ & $-0,889666667$ & $\mathrm{v}_{3} * \mathrm{v}_{3}$ & 0,791506778 \\
\hline & $\sum$ & 857,59 & $\sum \mathrm{v}$ & $-1,13687 \mathrm{E}-13$ & $\sum \mathrm{v}^{*} \mathrm{v}$ & 1,187320667 \\
\hline
\end{tabular}

\begin{tabular}{|l|c|c|}
\hline Number of measurement & $\mathrm{n}$ & $\mathbf{3}$ \\
\hline Arithmetical mean & $\mathrm{h}^{\prime}$ & $\mathbf{2 8 5 , 8 6 3 3 3 3 3}$ \\
\hline Standard deviation of each measurement & $\sigma_{\text {hi }}$ & $\mathbf{0 , 7 7 0}$ \\
\hline
\end{tabular}


Standard deviation of arithmetiacal mean $\sigma_{h i}{ }^{-}$

0,445

\begin{tabular}{|c|c|c|c|c|c|c|}
\hline \multicolumn{2}{|l|}{$2 \mathrm{~h}$} & \multirow{2}{*}{$\begin{array}{c}\mathrm{h}[\mathrm{m}] \\
285,2020\end{array}$} & \multicolumn{2}{|c|}{ deviation from the arithmetical mean } & \multicolumn{2}{|c|}{ the deviation squares } \\
\hline Topcon Hiper Pro & $2 \mathrm{~h}$ & & $\mathrm{v}_{1}=\mathrm{h}^{\prime}-\mathrm{h}_{1}$ & 0,202666667 & $\mathrm{~V}_{1} * \mathrm{v}_{1}$ & 0,041073778 \\
\hline Topcon Hiper V & $2 \mathrm{~h}$ & 285,5220 & $\mathrm{~V}_{2}=\mathrm{h}^{\prime}-\mathrm{h}_{2}$ & $-0,117333333$ & $\mathrm{~V} 2_{2} * \mathrm{~V}_{2}$ & 0,013767111 \\
\hline Leica & $2 \mathrm{~h}$ & 285,490 & $\mathrm{v}_{3}=\mathrm{h}^{\prime}-\mathrm{h}_{3}$ & $-0,085333333$ & $\mathrm{~V}_{3} * \mathrm{~V}_{3}$ & 0,007281778 \\
\hline & $\sum$ & 856,2140 & $\sum \mathrm{v}$ & $-1,13687 E-13$ & $\sum \mathrm{v}^{*} \mathrm{v}$ & 0,062122667 \\
\hline
\end{tabular}

\begin{tabular}{|l|c|c|}
\hline Number of measurement & $\mathrm{n}$ & $\mathbf{3}$ \\
\hline Arithmetical mean & $\mathrm{h}^{\prime}$ & $\mathbf{2 8 5 , 4 0 4 6 6 6 7}$ \\
\hline Standard deviation of each measurement & $\sigma_{\mathrm{hi}}$ & $\mathbf{0 , 1 7 6}$ \\
\hline Standard deviation of arithmetiacal mean & $\sigma_{\mathrm{hi}}{ }^{-}$ & $\mathbf{0 , 1 0 2}$ \\
\hline
\end{tabular}

$-6 \mathrm{~h}$

\begin{tabular}{|c|c|c|c|c|c|c|}
\hline & $\mathrm{h}[\mathrm{m}]$ & \multicolumn{2}{|c|}{ deviation from the arithmetical mean } & \multicolumn{2}{|c|}{ the deviation squares } \\
\hline Topcon Hiper Pro & $6 \mathrm{~h}$ & 285,4470 & $\mathrm{v}_{1}=\mathrm{h}^{\prime}-\mathrm{h}_{1}$ & 0,034 & $\mathrm{v}_{1} * \mathrm{v}_{1}$ & 0,001156 \\
\hline Topcon Hiper V & $6 \mathrm{~h}$ & 285,4890 & $\mathrm{~V}_{2}=\mathrm{h}^{\prime}-\mathrm{h}_{2}$ & $-0,008$ & $\mathrm{~V} 2_{2} * \mathrm{~V}_{2}$ & $6,4 \mathrm{E}-05$ \\
\hline Leica & $6 \mathrm{~h}$ & 285,507 & $\mathrm{v}_{3}=\mathrm{h}^{\prime}-\mathrm{h}_{3}$ & $-0,026$ & $\mathrm{v}_{3} * \mathrm{v}_{3}$ & 0,000676 \\
\hline & $\sum$ & 856,443 & $\sum \mathrm{v}$ & $\mathbf{0}$ & $\sum \mathrm{v}^{*} \mathrm{v}$ & 0,001896 \\
\hline
\end{tabular}

\begin{tabular}{|l|c|c|}
\hline Number of measurement & $\mathrm{n}$ & $\mathbf{3}$ \\
\hline Arithmetical mean & $\mathrm{h}^{\prime}$ & $\mathbf{2 8 5 , 4 8 1}$ \\
\hline Standard deviation of each measurement & $\sigma_{\mathrm{hi}}$ & $\mathbf{0 , 0 3 1}$ \\
\hline Standard deviation of arithmetiacal mean & $\sigma_{\text {hi }}^{-}$ & $\mathbf{0 , 0 1 8}$ \\
\hline
\end{tabular}

- $12 \mathrm{~h}$

\begin{tabular}{|l|c|c|c|c|c|c|}
\cline { 2 - 7 } \multicolumn{2}{c|}{} & $\mathrm{h}[\mathrm{m}]$ & \multicolumn{2}{l|}{ deviation from the arithmetical mean } & \multicolumn{2}{c|}{ the deviation squares } \\
\hline Topcon Hiper Pro & $12 \mathrm{~h}$ & 285,4560 & $\mathrm{v}_{1}=\mathrm{h}^{\prime}-\mathrm{h}_{1}$ & $-0,0237$ & $\mathrm{v}_{1} * \mathrm{v}_{1}$ & 0,000560111 \\
\hline Topcon Hiper V & $12 \mathrm{~h}$ & 285,4800 & $\mathrm{v}_{2}=\mathrm{h}^{\prime}-\mathrm{h}_{2}$ & $-0,0477$ & $\mathrm{v}_{2}{ }^{*} \mathrm{v}_{2}$ & 0,002272111 \\
\hline Leica & $12 \mathrm{~h}$ & 285,361 & $\mathrm{v}_{3}=\mathrm{h}^{\prime}-\mathrm{h}_{3}$ & 0,0713 & $\mathrm{v}_{3}{ }^{*} \mathrm{v}_{3}$ & 0,005088444 \\
\hline & $\sum$ & $\mathbf{8 5 6 , 2 9 7}$ & $\sum \mathrm{v}$ & $\mathbf{5 , 6 8 4 3 4 E - 1 4}$ & $\sum \mathrm{v}^{*} \mathrm{v}$ & $\mathbf{0 , 0 0 7 9 2 0 6 6 7}$ \\
\cline { 2 - 7 } & & & & &
\end{tabular}

\begin{tabular}{|l|c|c|}
\hline Number of measurement & $\mathrm{n}$ & $\mathbf{3}$ \\
\hline Arithmetical mean & $\mathrm{h}^{\prime}$ & $\mathbf{2 8 5 , 4 3 2 3 3 3 3}$ \\
\hline Standard deviation of each measurement & $\sigma_{\mathrm{hi}}$ & $\mathbf{0 , 0 6 3}$ \\
\hline Standard deviation of arithmetiacal mean & $\sigma_{\mathrm{hi}}^{-}$ & $\mathbf{0 , 0 3 6}$ \\
\hline
\end{tabular}

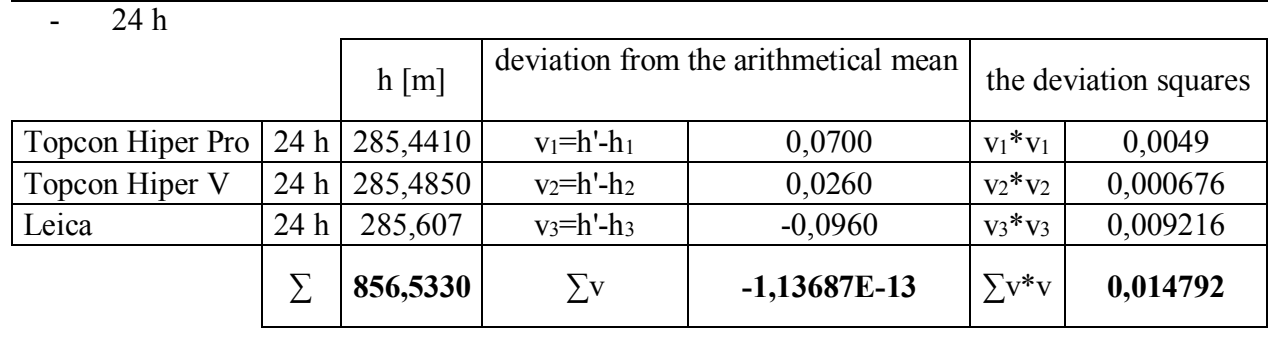




\begin{tabular}{|l|c|c|}
\hline Arithmetical mean & h' $^{\prime}$ & $\mathbf{2 8 5 , 5 1 1}$ \\
\hline Standard deviation of each measurement & $\sigma_{\text {hi }}$ & $\mathbf{0 , 0 8 6}$ \\
\hline Standard deviation of arithmetiacal mean & $\sigma_{\text {hi }}^{-}$ & $\mathbf{0 , 0 5 0}$ \\
\hline
\end{tabular}

Table 7. shows standard errors of the arithmetical mean based on time.

Table 7. Standard errors of the arithmetical mean.

\begin{tabular}{|c|c|c|c|}
\hline time & $\mathbf{Y}[\mathbf{m}]$ & $\mathbf{X}[\mathbf{m}]$ & $\mathbf{h}[\mathbf{m}]$ \\
\hline $\mathbf{1} \mathbf{~ h}$ & 0,155 & 0,106 & 0,445 \\
\hline $\mathbf{2} \mathbf{~ h}$ & 0,016 & 0,251 & 0,102 \\
\hline $\mathbf{6} \mathbf{~ h}$ & 0,021 & 0,018 & 0,018 \\
\hline $\mathbf{1 2} \mathbf{~ h}$ & 0,021 & 0,060 & 0,036 \\
\hline $\mathbf{2 4} \mathbf{~ h}$ & 0,019 & 0,003 & 0,050 \\
\hline
\end{tabular}

Fig. 5. graphically shows the standard errors of the arithmetical means based on time.

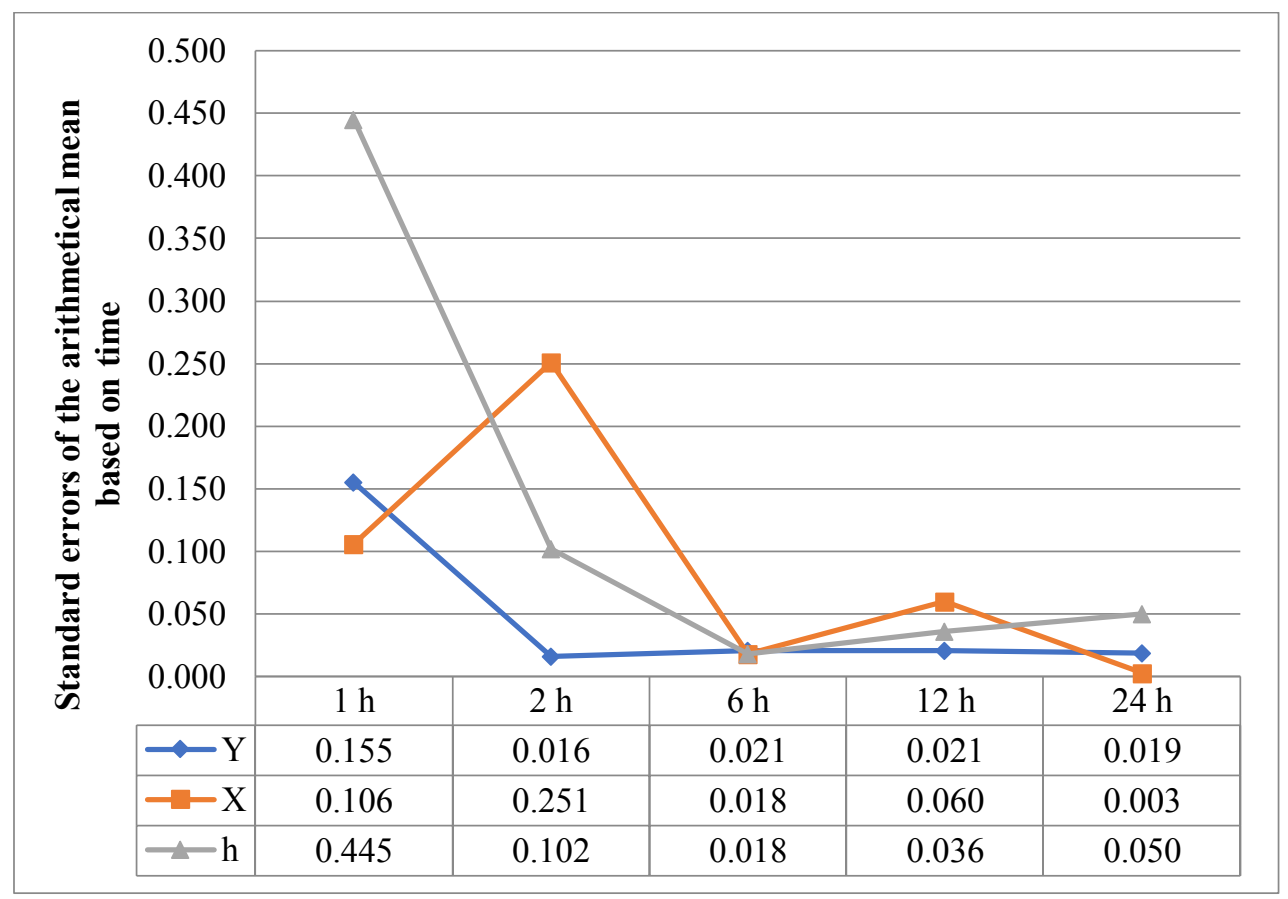

Fig. 5. Standard errors of the arithmetical mean based on time.

The expected trend of the accuracy increase with the prolongation of the observation duration is seen. The result deviates from the average at $24 \mathrm{~h}$, since the best accuracy would be expected. This is justified with the altitude component not being conditioned with the length of the observation duration. Better results are obtained with a longer period, but generally, the accuracy improves up to $6 \mathrm{~h}$ measurement and later oscillates for a few cms. Based on that, it can be concluded that for the monitoring needs the $24 \mathrm{~h}$ GNSS measurement is not necessary to be performed, but a $6 \mathrm{~h}$ capture at the beforehand good measurement planning is enough.

The experiment to compare the altitude component with the RTS and GNSS surveying measurement was performed to improve the altitude component as well. The experiment was 
executed in the open terrain, due to the elimination of potential disturbances and at the beforehand measurement planning due to good satellite's arrangement.

\section{Altitude component comparative analysis}

The analysis is based on the change of the receiver's altitude each $60 \mathrm{~s}$ for approximately $5 \mathrm{~cm}$. From 10 (on RTS) to 100 (GNSS) readings per second were performed in this time (Fig.6). 5379 measurements were gained during the experiment with the instrument. The RTS surveying measurement was performed in the local coordinate system and GNSS surveying measurements in ETRS coordinate system; they were later transformed into the unified Cartesian coordinate system due to the more detailed analysis [4].

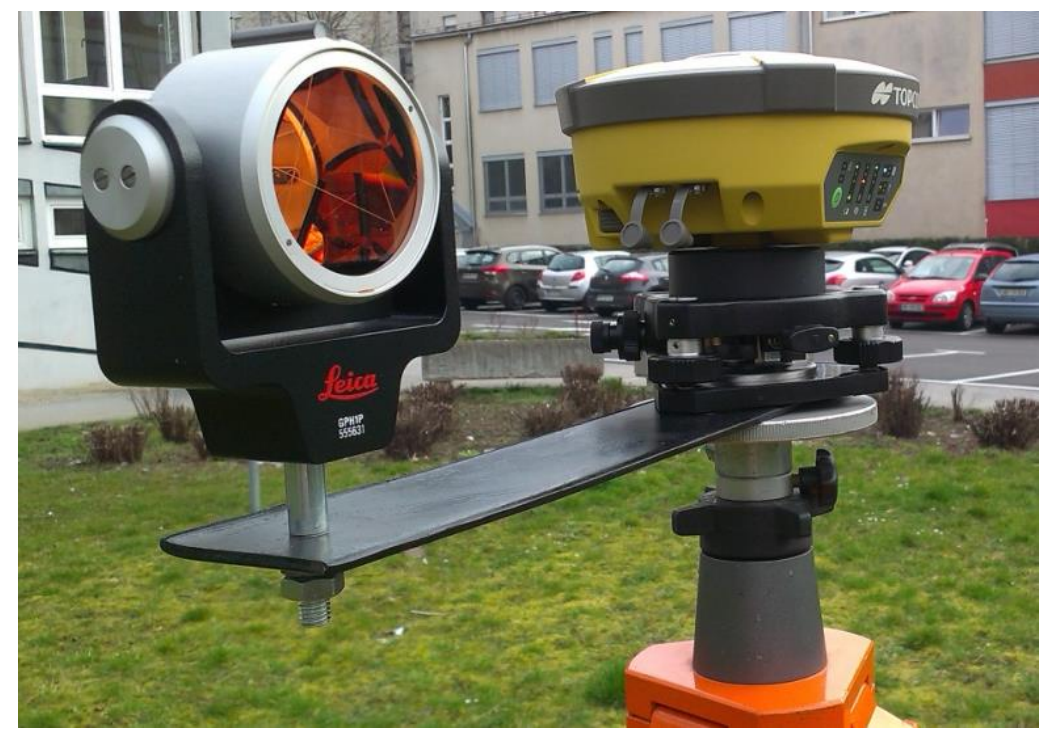

Fig. 6. The display of the Leica GPH1P prism.

11 altitude changes were performed within the terrain capture, which is seen in Fig. $7 .$. The emphasis in this experiment was on increasing the number of measurements with the GNSS surveying measurement on 100HZ. Thus, the accuracy was increased. 


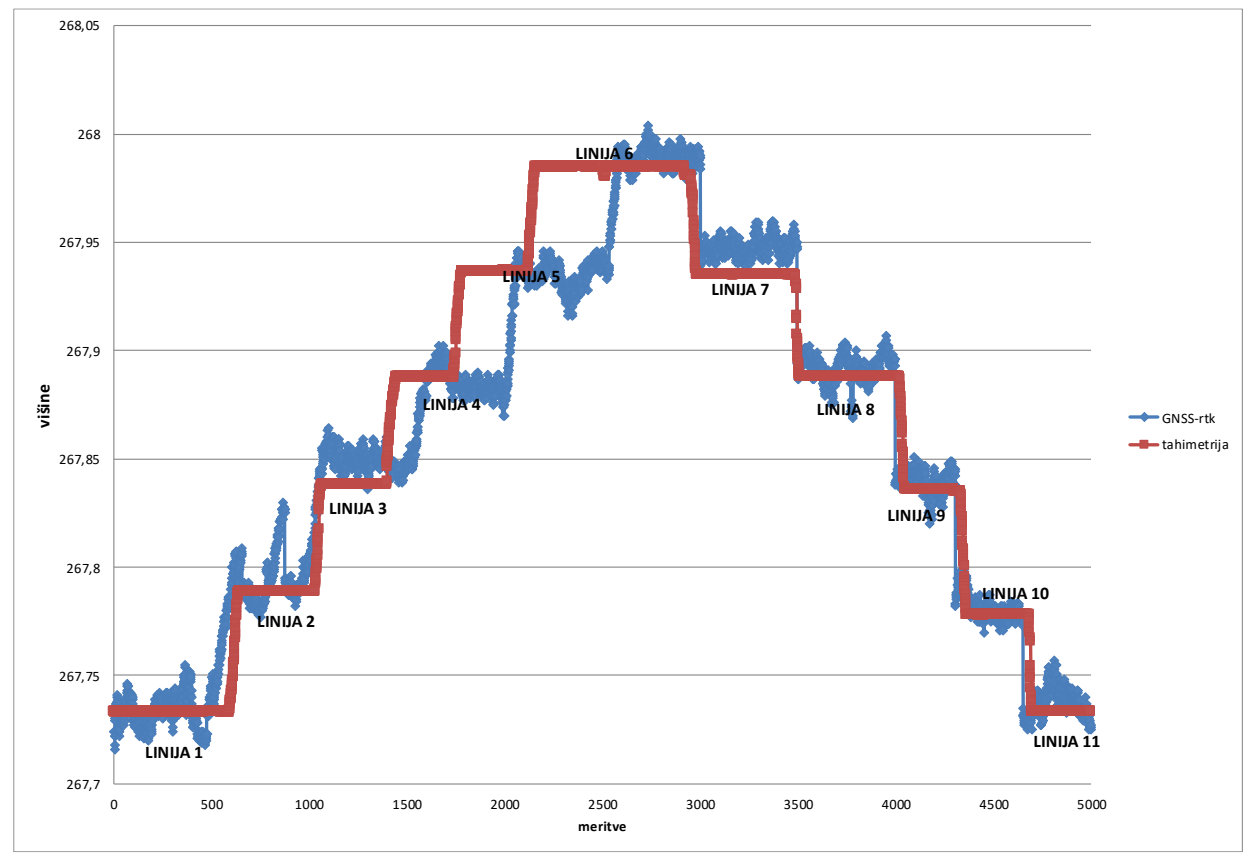

Fig. 7. The display of 11 altitude changes with both methods.

Later, only the analyses of 2 lines and a total result of the analysis will be shown.

The graphs were illustrated based on those results. The graphs were divided into the lines (i.e. prism's or the GNSS antenna's altitude position) which are marked on the upper Fig. 8. The first 586 points were used to illustrate the line's 1 graph and Fig. 8. was obtained. Blue colour indicates the average value of the measurement [4].

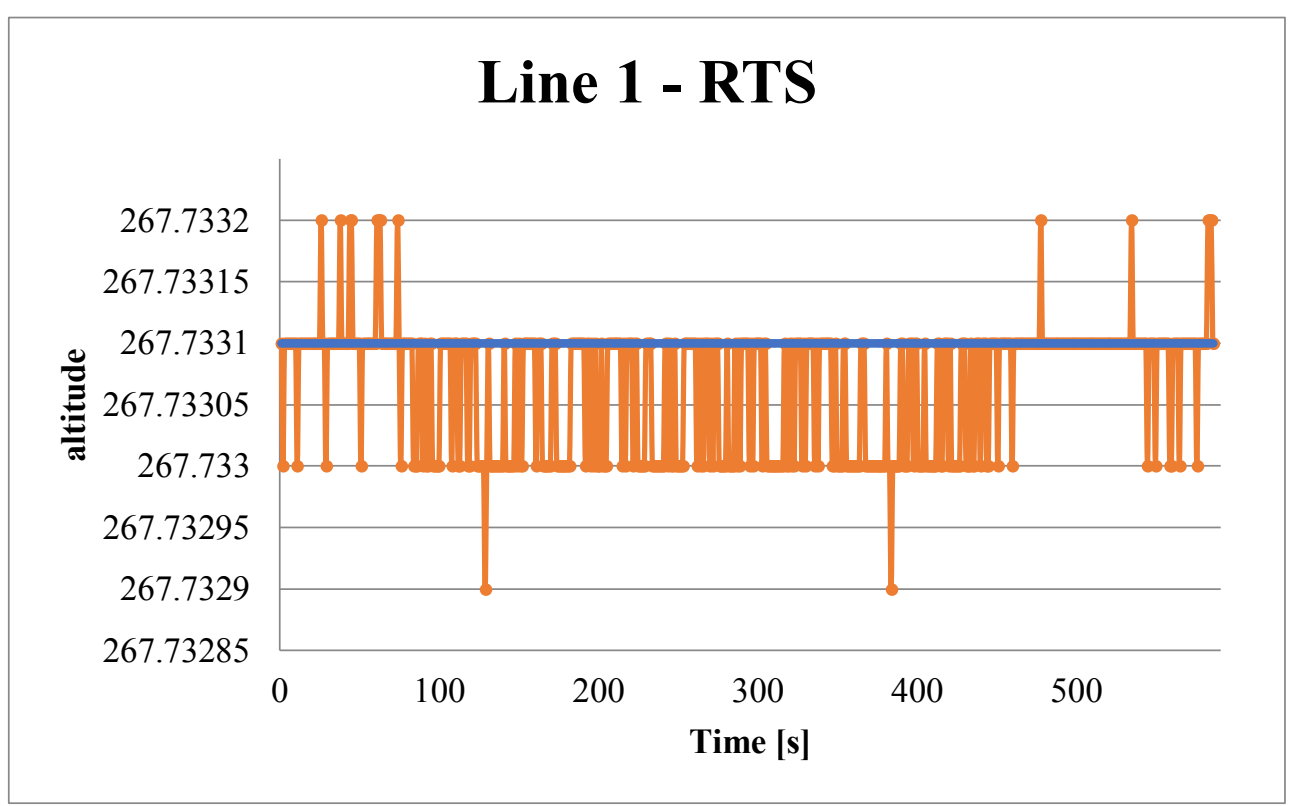

Fig. 8. The display of altitude coordinates from the 1st to 586th point. 
Fig. 9. for the GNSS surveying measurements was illustrated in the same way; the first 438 points were used, and the average value of the altitude coordinates was added. The red colour indicates the average value of the measurement [4].

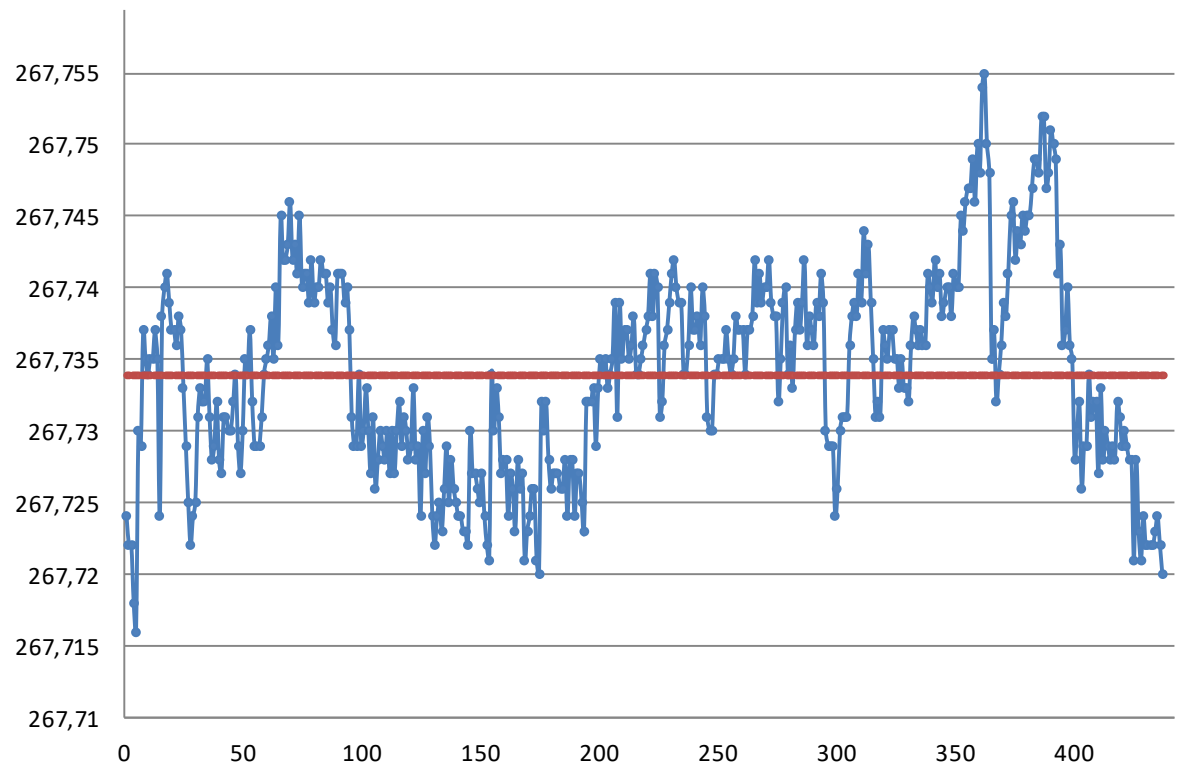

Fig. 9. The display of the altitude coordinates from the 1st to the 586th point measured with GNSS.

Table 8. The measurements' values, altitudes' arithmetical means, measurement's standard deviations and the deviation from the reference value for line 1 .

\begin{tabular}{|c|c|c|}
\hline & RTS Leica TS50 & GNSS Topcon Hiper V \\
\hline Number of measurements & 586 & 438 \\
\hline Altitude arithmetical mean $[\mathrm{m}]$ & 267,7331 & 267,7340 \\
\hline Standard deviation $[\mathrm{mm}]$ & 0,0022 & 0,3328 \\
\hline Divation of referet mean $[\mathrm{mm}]$ & - & 0,9 \\
\hline
\end{tabular}




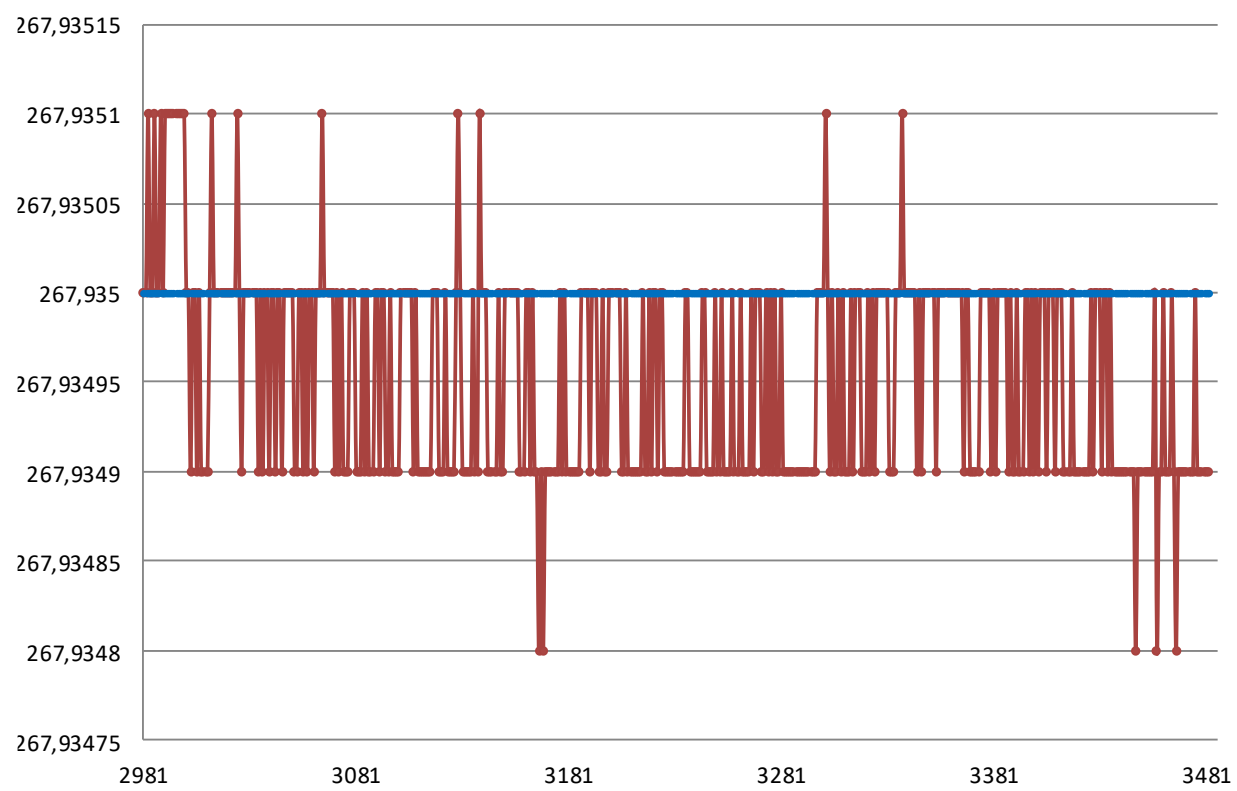

Fig. 10. The display of altitude coordinates from 2981st to 3482 nd point measured with RTS.

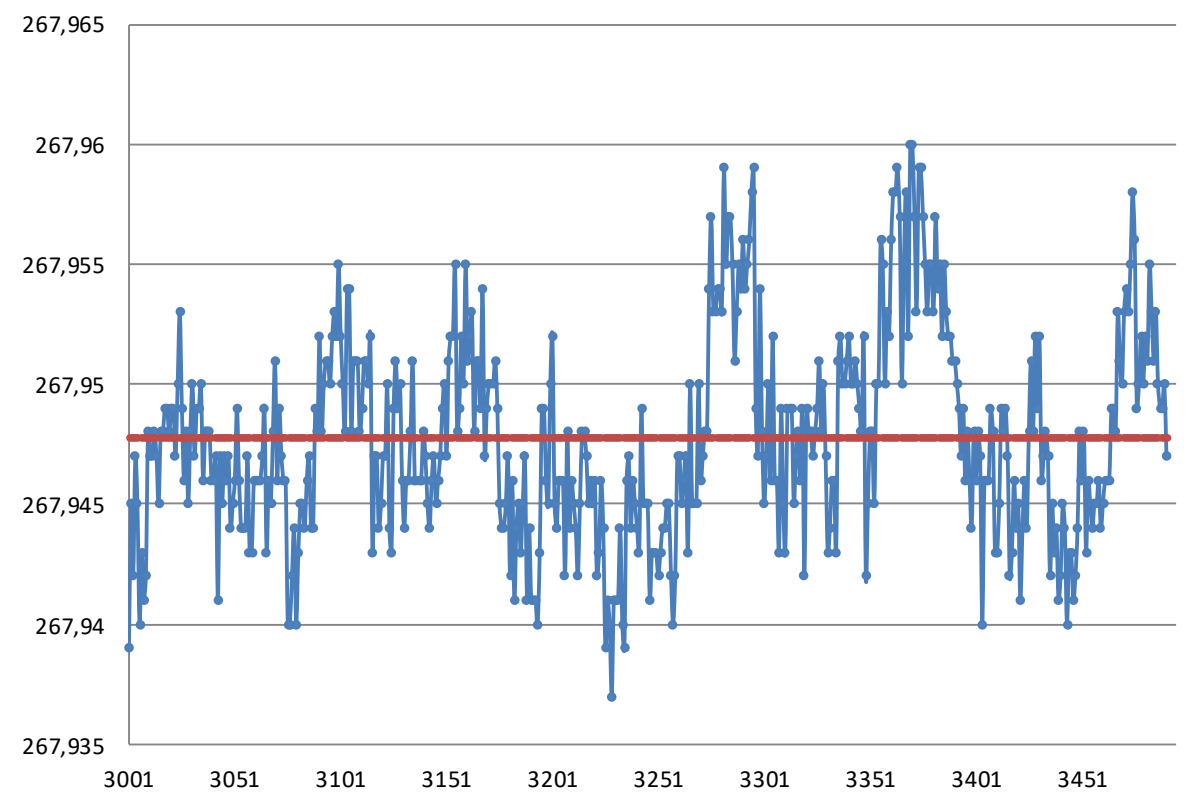

Fig. 11. The display of altitude coordinates from 3001st to 3491 st point measured with GNSS.

Table 9. The measurements' values, altitudes' arithmetical means, measurement's standard deviations and the deviation from the reference value for line 7.

\begin{tabular}{|c|c|c|}
\hline & RTS Leica TS50 & GNSS Topcon Hiper V \\
\hline Number of measurements & 502 & 491 \\
\hline Altitude arithmetical mean [m] & 267,9350 & 267,9478 \\
\hline Standard deviation [mm] & 0,0026 & 0,1920 \\
\hline Divation of referet mean [mm] & - & 12,8 \\
\hline
\end{tabular}


The results were compared in the lower Table 9 into which the average mean of all altitudes' arithmetical means, measurements' standard deviations and deviations from the reference measurement's value were added [4].

Table 9. Results of all lines.

\begin{tabular}{|c|c|c|c|c|c|}
\hline & \multicolumn{2}{|c|}{ RTS } & \multicolumn{2}{c|}{ GNSS } & \\
\hline & $\begin{array}{c}\text { Average } \\
\text { mean [m] }\end{array}$ & $\begin{array}{c}\text { Standard } \\
\text { deviation of } \\
\text { each } \\
\text { measurement } \\
{[\mathrm{mm}]}\end{array}$ & $\begin{array}{c}\text { Average } \\
\text { mean [m] }\end{array}$ & $\begin{array}{c}\text { Standard } \\
\text { deviation of } \\
\text { each } \\
\text { measurement } \\
{[\mathrm{mm}]}\end{array}$ & $\begin{array}{c}\text { Deviation of } \\
\text { referent mean } \\
{[\mathrm{mm}]}\end{array}$ \\
\hline 1 & 2 & 3 & 4 & 5 & 6 \\
\hline LINE1 & 267,7331 & 0,0022 & 267,7340 & 0,3328 & 0,9 \\
\hline LINE 2 & 267,7887 & 0,0027 & 267,7948 & 0,7298 & 6,1 \\
\hline LINE 3 & 267,8381 & 0,0032 & 267,8497 & 0,2339 & 11,6 \\
\hline LINE 4 & 267,8877 & 0,0034 & 267,8856 & 0,3135 & 2,1 \\
\hline LINE 5 & 267,9396 & 0,0033 & 267,9353 & 0,2706 & 1,6 \\
\hline LINE 6 & 267,9846 & 0,0171 & 267,9896 & 0,2172 & 5,0 \\
\hline LINE 7 & 267,9350 & 0,0026 & 267,9478 & 0,1920 & 12,8 \\
\hline LINE 8 & 267,8880 & 0,0026 & 267,8920 & 0,2874 & 4,0 \\
\hline LINE 9 & 267,8359 & 0,0032 & 267,8398 & 0,3205 & 3,9 \\
\hline LINE 10 & 267,7778 & 0,0029 & 267,7816 & 0,2984 & 3,8 \\
\hline LINIJA & 267,7333 & 0,0028 & 267,7378 & 0,3570 & 4,5 \\
\hline 11 & & & & & \\
\hline $\begin{array}{c}\text { Average } \\
\text { mean }\end{array}$ & 267,8493 & 0,0042 & 267,8535 & 0,3230 & $\mathbf{5 , 1}$ \\
\hline
\end{tabular}

The biggest deviation from the reference value appears in line $3(11.6 \mathrm{~mm})$ and in line 7 $(12.8 \mathrm{~mm})$ as seen from Table 9. These results are ascribed to potential worse satellite's division and partly also to the unpredictable disturbances on the terrain. The results can, of course, be improved with postprocessing and the introduction of the new parameters.

Individual line deviations from the reference value are shown in the last column of Table 9. The result represents the average value of all deviations from the reference value [4].

\section{Conclusion}

Today's development has interfered also in geodesy. Therefore, we meet with the instruments and highly sensitive and accurate equipment with which, even so tough works, can be performed. In construction, especially in constructions' testing, the shifts, vibrations and static responses with great reliability and accuracy can be monitored. We must know the development has interfered also in construction and now various constructions are built on that kind of terrain which decades ago could not be imagined. Due to the extreme terrain, we were obligated to test constructions with such equipment which was not dependent on altitude, inaccessibility and distance from the reference points. For this reason, the GNSS equipment is used; it is independent of the mentioned circumstances. Testing needs to be performed to trust the GNSS surveying measurements with as much reliability as possible. It is for that reason why two independent GNSS equipment testing was performed. The time analysis of data capture was performed in the first case. It provided tangible results regarding the planning of the GNSS surveying measurement and how long is it necessary to capture data to obtain the desired accuracy. Since the emphasis was on the altitude analysis, the other experiment where the altitude changes with RTS and GNSS surveying measurement comparison was performed. It is necessary to mention that at the GNSS surveying 
measurement the number of data capture was increased to $100 \mathrm{~Hz}$. That provided comparable results but not yet sufficiently accurate to determine the shift in the vertical direction with the GNSS surveying measurement. At such massive data capture with the GNSS surveying measurement, it would be reasonable to use this method for long-term monitoring where with the averaging tangible values could be obtained. Such a method is already used around the world as monitoring 3D pylons' movement on the bridges where the GNSS antenna is attached on top and signals out the data for $24 \mathrm{~h}$ a day through all year.

Our testing showed it is reasonable to leave the GNSS antenna for at least 6 hours to determine coordinates for the needs of monitoring. Regarding the altitude comparison, it was noted the GNSS surveying measurement in the range of deviation from $1 \mathrm{~mm}$ to $13 \mathrm{~mm}$ where bigger shifts $(>2 \mathrm{~cm})$ are enough.

\section{References}

1. M. Rak, Ispitivanje konstrukcija (University of Rijeka, Croatia, 2005)

2. B. Kovačič, Geodetski vestnik 48/1, 32-39 (2004)

3. B. Stopar, P. Pavlovčič Prešeren, K. Kozmus Trajkovski, GPS v geodeziji, študijsko gradivo (University of Ljubljana, Ljubljana, 2008)

4. N. Božič, Analiza določitve višin z različnimi geodetskimi metodami, Diploma work (Universoty of Maribor, Slovenia, 2016)

5. A. Marendić, Z. Kapović, R. Paar, Geodetski list 3, 175 -190 (2013) 